\title{
Diversidade e ocorrência de peixes na área de influência da UHE Mogi Guaçu e lagoas marginais, bacia do alto rio Paraná, São Paulo, Brasil
}

\author{
Cristina da Silva Gonçalves ${ }^{1,2}$ \& Francisco Manoel de Souza Braga ${ }^{1}$
}

\author{
${ }^{I}$ Departamento de Zoologia, Instituto de Biociências, \\ Universidade Estadual Paulista Júlio de Mesquita Filho - UNESP, \\ Av. 24-A, 1515, CP 199, CEP 13505-900, Rio Claro, SP, Brasil \\ ${ }^{2}$ Autor para correspondência: Cristina da Silva Gonçalves, e-mail: csilg@rc.unesp.br
}

GONÇALVES, C.S. \& BRAGA, F.M.S. 2008. Fish diversity and occurrence in the influence area of the Mogi Guaçu reservoir and oxbow lakes, high Paraná river basin, São Paulo, Brazil. Biota Neotrop. 8(2): http:// www.biotaneotropica.org.br/v8n2/pt/abstract?article+bn02008022008.

\begin{abstract}
The high Paraná river basin includes the largest rivers from São Paulo State and a great ichthyofauna diversity with 236 species. The aim of this study was to describe the fish fauna composition from Mogi Guaçu hydroelectric dam and oxbow lakes downstream reservoir, according to species abundance temporal variations. A total of 2.341 individuals (85,8 kg biomass) belonging to 41 species were collected during August 2005 to July 2006. From this, 31 species were found in the reservoir and 24 in the oxbow lakes showing the Curimatidae (Cyphocharax modestus and Steindachnerina insculpta) and Characidae (Hyphessobrycon eques and H. bifasciatus) dominance and many rare species. The abundance and biomass cumulative curves showed the numerical dominance in reservoir and biomass in oxbow lakes, reflecting an environment more and less disturbed, respectively. Similar values of Shannon's diversity and evenness were found to reservoir and oxbow lakes. In general, the highest values were obtained to the wet season and the smaller to the dry, but this variation were not sufficient to detect significant differences between areas, neither seasons. The species identities are not considered in these indexes computation, being insensitive to ichthyofauna composition differences between the reservoir and the oxbow lakes. The interpretation of these results should be taken carefully because despite the Shannon's indexes showed no differences in fish fauna composition between areas, the similarity analyses using the Morisita-Horn index showed low similarity among them. Moreover, the ichthyofauna found in the studied area was composed by typical species from high Paraná river basin which indicates a good condition with native species only, despite the impacts commonly caused by hydroelectric dams. We suggest that the dam regulation and the sand extraction from the river bed are affecting the flood pulses and consequently the oxbow lake's ichthyofauna.
\end{abstract}

Keywords: ichthyofauna, reservoir, floodplain, similarity.

GONÇALVES, C.S. \& BRAGA, F.M.S. 2008. Diversidade e ocorrência de peixes na área de influência da UHE Mogi Guaçu e lagoas marginais, bacia do alto rio Paraná, São Paulo, Brasil. Biota Neotrop. 8(2): http:// www.biotaneotropica.org.br/v8n2/pt/abstract?article+bn02008022008.

Resumo: A bacia do alto Paraná apresenta os rios de maior porte do Estado de São Paulo e uma ictiofauna bastante diversa, com 236 espécies. Este estudo visou caracterizar a composição ictiofaunística do reservatório da UHE Mogi Guaçu e de um conjunto de lagoas marginais naturais a jusante da represa, de acordo com a variação temporal da abundância das espécies. Durante agosto de 2005 a julho de 2006, foram coletados 2.341 exemplares pertencentes a 41 espécies. Na represa foram registradas 31 espécies e nas lagoas marginais 24, revelando uma dominância de espécies de Curimatidae (Cyphocharax modestus e Steindachnerina insculpta) e Characidae (Hyphessobrycon eques e $H$. bifasciatus) e um número expressivo de espécies raras. As curvas cumulativas de abundância e biomassa indicaram que na represa as espécies foram dominantes em número e nas lagoas em biomassa, refletindo um ambiente sob ações antrópicas e outro menos perturbado, respectivamente. A represa e as lagoas marginais apresentaram valores próximos de diversidade e eqüitabilidade de Shannon. No geral, os maiores valores foram obtidos durante o período chuvoso e os menores durante o período seco, porém esta variação não foi suficiente para a ANOVA detectar diferenças significativas entre os ambientes, nem entre os períodos. A interpretação destes resultados deve ser feita com cautela, pois apesar dos índices de diversidade e eqüitabilidade de Shannon não terem evidenciado as diferenças na composição da ictiofauna, a análise de similaridade pelo índice de MorisitaHorn apontou que a ictiofauna da represa e das lagoas marginais apresentam baixa similaridade entre si. Além disso, a ictiofauna nos ambientes estudados foi composta por peixes típicos da bacia do alto Paraná indicando uma condição que, embora alterada pela construção da UHE, apresenta espécies essencialmente nativas desta região. Sugere-se que o controle da vazão do rio pela UHE Mogi Guaçu e a extração de areia do leito estejam influenciando os pulsos de inundação e conseqüentemente a ictiofauna das lagoas marginais.

Palavras-chave: ictiofauna, represa, planície de inundação, similaridade. 


\section{Introdução}

A bacia do rio Paraná está inserida no segundo maior sistema de drenagem da América do Sul (Lowe-McConnell 1999), abrigando uma ictiofauna bastante diversa, mas ainda pouco conhecida. A região do alto Paraná inclui os cursos de água de maior porte do Estado de São Paulo e é conhecida pela grande diversidade de peixes, com 38 famílias, 236 espécies nativas descritas e cerca de 50 novas espécies em fase de descrição (Langeani et al. 2007).

No Brasil, a construção de usinas hidrelétricas (UHEs) alcançou grande desenvolvimento especialmente nas décadas de 1920 a 1930 , 1950 e 1970 (Tundisi 2003, Agostinho et al. 2007). Mais de 600 barragens já foram construídas e ocupam uma área de aproximadamente $40.000 \mathrm{~km}^{2}$, com volume de $6,5 \times 10^{11} \mathrm{~m}^{3}$, com o principal intuito de gerar energia elétrica (Agostinho et al. 2005). Cerca de $85 \%$ da energia produzida no Brasil é gerada em UHEs (Tundisi 2003) e quase $70 \%$ provém de reservatórios da bacia do rio Paraná (Agostinho et al. 2007). Todos os principais rios do Estado de São Paulo possuem grandes represas. Segundo Mioto et al. (2000) existem cerca de 12 pequenas centrais hidrelétricas ( $\mathrm{PCHs}$ ) na bacia do rio Mogi Guaçu, das quais cinco encontram-se instaladas no alto rio Mogi Guaçu, incluindo a UHE Mogi Guaçu.

Apesar dos impactos negativos causados ao meio ambiente e à ictiofauna, a construção de UHEs no Brasil ainda é uma prática bastante comum (Agostinho et al. 2004a, Agostinho et al. 2007). Estudos em reservatórios gerados pela construção de UHEs têm tido importância cada vez maior devido ao grande número desses ecossistemas artificiais (Agostinho et al. 2007) e servem de referência no planejamento da instalação de futuras UHEs. O principal problema causado pela formação de um reservatório é a ocorrência de uma mudança drástica no ambiente aquático em um prazo relativamente curto (Castro \& Arcifa 1987), transformando o ambiente lótico em lêntico rapidamente (Maitland \& Morgan 1997). Reservatórios criados a partir do represamento de um rio proporcionam um ambiente novo e alterado para a comunidade íctica (Tundisi 1981), que se refletirá principalmente, na diversidade de espécies que irão colonizar o reservatório, na disponibilidade de alimento e nas relações interespecíficas (Castro \& Arcifa 1987).

Segundo Barbieri et al. (2000), alguns dos fatores que têm contribuído para a sobrevivência e reprodução de várias espécies de peixes no Mogi Guaçu, incluem a quantidade significativa de lagoas marginais naturais, trechos de mata nativa preservados por Unidades de Conservação, a grande capacidade de depuração e os poucos represamentos ao longo do curso do rio. Em seu trecho médio, o rio Mogi Guaçu apresenta uma extensa planície alagável, com mais de 90 lagoas marginais de dimensões variadas e diferentes graus de conectividade com o rio (Vieira \& Verani 2000). Este trecho compreende a região de Cachoeira de Emas em Pirassununga e o município de Luis Antônio (SP), que tem sido exaustivamente estudado por diversos pesquisadores (Godoy 1975, Santos \& Pires 2000). Diferentemente do trecho médio, a região do alto rio Mogi Guaçu, próxima à sub-bacia do rio do Peixe, onde a área desse estudo está localizada, carece de pesquisas referentes à sua ictiofauna.

O principal objetivo deste trabalho foi caracterizar a composição ictiofaunística do reservatório da UHE Mogi Guaçu e de um conjunto de lagoas marginais naturais da planície de inundação na fazenda Campininha, município de Mogi Guaçu (SP), de acordo com a variação temporal na abundância das espécies durante o período de estudo. Para isso, foram analisadas a constância de ocorrência, a diversidade, a dominância e a similaridade das espécies entre os dois tipos de ambientes amostrados.

\section{Material e Métodos}

\section{1. Área de estudo}

O rio Mogi Guaçu possui 473 km de extensão, nasce no Estado de Minas Gerais a $1.594 \mathrm{~m}$ de altitude no município de Bom Repouso
(Brigante \& Espíndola 2003). No Estado de São Paulo, deságua no rio Pardo numa altitude de $490 \mathrm{~m}$, no município de Pontal (SP), e se junta ao rio Grande (CBH-Mogi 1999), percorrendo a maior parte de seu curso (84\%) em território paulista (Brigante \& Espíndola 2003).

A UHE Mogi Guaçu (22 $21^{\prime}$ 'S e $46^{\circ} 51^{\prime} \mathrm{W}$ ) (Figura 1) foi construída em 1995 (Brandimarte et al. 2005), iniciando suas operações em 1999 pela AES-Tietê. Tem por finalidade garantir o abastecimento de água para os municípios vizinhos e gerar aproximadamente 7,2 MW de energia (AES-Tietê 2007), o que a caracteriza como uma PCH (Mioto et al. 2000). Ocupa uma área de $5,73 \mathrm{~km}^{2} \mathrm{com} 8 \mathrm{~km}$ de extensão e $32,89 \times 10^{6} \mathrm{~m}^{3}$ de volume (AES-Tietê 2007). Outras características incluem: extensão da barragem de 170 m, 7 m de queda d'água, duas turbinas instaladas, quatro comportas e uma escada lateral para peixes (Brandimarte et al. 2005, AES-Tietê 2007) com 21 degraus. O tempo de residência da água é de 72 horas (Brandimarte et al. 2005). A pesca esportiva e profissional é prática comum, porém em pequena escala, e a extração de areia em alguns trechos do reservatório é intensa (obs. pess.). A vegetação aquática é composta por 17 espécies de macrófitas emersas e flutuantes, sendo as espécies Brachiaria subquadripara e Eichornia crassipes as mais abundantes (Cavenaghi et al. 2005). Os pontos de coleta no reservatório foram escolhidos de forma que abrangessem a área de influência da UHE. Dessa forma, alguns pontos no rio do Peixe, afluente da margem esquerda do rio Mogi Guaçu, foram também amostrados.

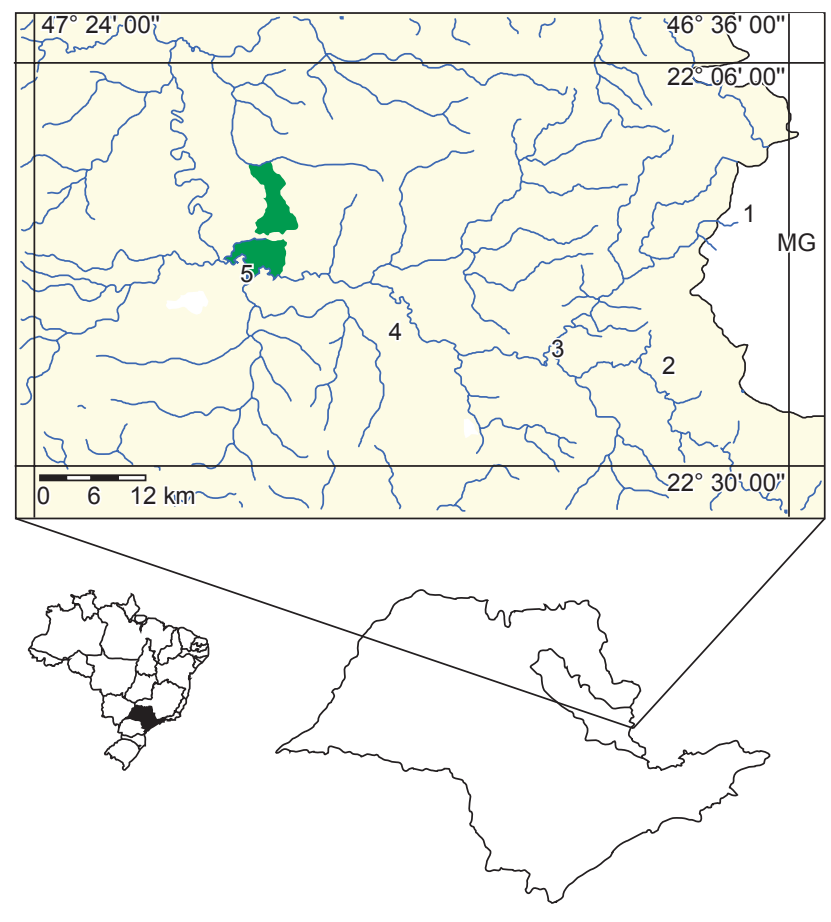

Figura 1. Mapa da bacia do rio Mogi Guaçu no Estado de São Paulo indicando a área de estudo. A área verde representa a Estação Ecológica Mogi Guaçu (fazenda Campininha). 1) nascentes do rio Mogi Guaçu no estado de Minas Gerais (MG); 2) rio do Peixe; 3 ) reservatório da UHE Mogi Guaçu; 4) Rio Mogi Guaçu; 5) lagoas marginais da Estação Ecológica Mogi Guaçu. (Mapa modificado de CRIA - Centro de Referência em Informação Ambiental).

Figure 1. São Paulo State map showing Mogi Guaçu river basin which the study area is included. The green area represents the Mogi Guaçu Ecological Station (Campininha farm). 1) Mogi Guaçu headwaters in Minas Gerais State (MG); 2) Peixe river; 3) Mogi Guaçu reservoir; 4) Mogi Guaçu River; 5) Ecological Station oxbow lakes location. (Map modified from CRIA Centro de Referência em Informação Ambiental). 
A Estação Ecológica Mogi Guaçu, também conhecida como fazenda Campininha (latitudes $22^{\circ} 16^{\prime}$ e $22^{\circ} 18^{\prime} \mathrm{S}$ e longitudes $47^{\circ} 09^{\prime} \mathrm{e}$ $47^{\circ} 12^{\prime}$ W) (Figura 1) é uma Unidade de Conservação com 980,71 ha, localizada no distrito de Martinho Prado Jr., município de Mogi Guaçu (SP). Possui pequenas lagoas marginais naturais e artificiais, com ligação sazonal com o rio durante o período de inundação. As quatro lagoas escolhidas para este estudo (Catingueiro, Barrinha, Pedra e Fundão), estão localizadas próximas da margem direita do rio Mogi Guaçu, distantes aproximadamente $43 \mathrm{~km}$ do reservatório da UHE Mogi Guaçu. Durante o período da cheia, quando ocorre o pulso de inundação, a água pode alcançar as lagoas pelo transbordamento lateral do rio.

As características predominantes de cada ambiente (represa e lagoas marginais) como profundidade, tipo de fundo, vegetação aquática e do entorno, encontram-se sumarizadas na Tabela 1.

\section{Amostragem}

As amostras foram obtidas entre agosto de 2005 a julho de 2006, compreendendo seis amostragens em cada ambiente (no reservatório: agosto, outubro e dezembro/05, fevereiro, abril e junho/06; nas lagoas marginais: agosto e dezembro/05, janeiro, março, junho e julho/06). As coletas foram realizadas com esforço padronizado, utilizando redes de espera (malhas 1,$5 ; 2,0 ; 2,5 ; 3,0 ; 4,0$ e $5,0 \mathrm{~cm}$ entre nós adjacentes), cada uma com $10 \mathrm{~m}$ de comprimento para cada lagoa (totalizando $40 \mathrm{~m} / \mathrm{malha}$ ) e $40 \mathrm{~m}$ para a represa, além de puçá e quatro armadilhas do tipo covo médias. As redes e os covos eram instalados durante a tarde e retirados na manhã do dia seguinte. Antes da despesca, o puçá era passado próximo da vegetação marginal por 10 vezes em dois pontos.

Os peixes capturados foram fixados em formalina a $10 \%$ durante três a cinco dias e posteriormente conservados em álcool a 70\%. Os peixes foram identificados em nível específico de acordo com Britski et al. (1999) e posteriormente conferidos por especialistas. Devido a dúvidas na identificação dos exemplares de Prochilodus lineatus e $P$. vimboides, estes foram agrupados em Prochilodus spp. Os exemplares foram medidos em milímetros quanto ao comprimento total e padrão utilizando-se um ictiômetro e obtido o peso total, em gramas, com balança analítica. O material testemunho encontra-se depositado na coleção de peixes do Departamento de Zoologia da Universidade Estadual Paulista, campus de Rio Claro (SP).
As características físico-químicas da água medidas foram: temperatura da água (termômetro de mercúrio), $\mathrm{pH}$ (pHmetro digital) e oxigênio dissolvido (método de Winkler, segundo Moraes 2001).

\section{Análise dos dados}

A constância de ocorrência das espécies foi determinada utilizando-se a relação entre o número de coletas contendo a espécie em questão (p) e o número total de coletas realizadas $(\mathrm{P})$, expressa em porcentagem por $\mathrm{C}=\mathrm{p} \times 100 / \mathrm{P}$. A espécie foi considerada residente (ou constante) se $\mathrm{C} \geq 50 \%$, acessória se $25 \% \leq \mathrm{C}>50 \%$ ou acidental se $\mathrm{C}<25 \%$ (Dajoz 1972). A distinção dos exemplares jovens e adultos seguiu Vazzoler (1996).

Para cada amostra, a diversidade alfa foi estimada pelo índice de Shannon para o número de indivíduos, de acordo com a fórmula $\mathrm{H}^{\prime}=-\Sigma\left(\mathrm{p}_{\mathrm{i}}\right) \cdot\left(\log _{10} \cdot \mathrm{p}_{\mathrm{i}}\right)$, onde $\mathrm{p}_{\mathrm{i}}$ é a razão entre o número de exemplares da espécie i pelo número total de exemplares capturados. A uniformidade da distribuição das espécies foi calculada através da equiitabilidade de Shannon pela equação $E=H^{\prime} / \log _{10} . S$, onde $S$ é o número total de espécies encontradas (Magurran 2004). Para verificar diferenças na diversidade de espécies entre a represa e as lagoas marginais durante os períodos seco e chuvoso, foram utilizadas análises de variância (ANOVA "two-way"), respeitando-se os pressupostos de normalidade e homocedasticidade dos dados (Zar 1999) e o nível de significância $(\alpha)$ de $5 \%$ para as análises. De acordo com os valores médios de 30 anos de pluviosidade e temperatura do ar, fornecidos pelo posto meteorológico da fazenda Campininha (D4-100), o período seco foi definido pelos meses compreendidos entre abril e setembro e o chuvoso, de outubro a março.

A diversidade beta foi estimada pelo índice de Morisita-Horn (Magurran 2004) usando-se os valores de abundância total das espécies para cada ambiente (represa e lagoas marginais) e por amostra, sendo o resultado exibido na forma de dendrograma. O uso do índice de Morisita-Horn independe do tamanho das amostras e da diversidade das espécies (Wolda 1981). O método de ligação utilizado foi a métrica UPGMA por atribuir similaridade entre os pares de forma menos extrema. O coeficiente de correlação de Pearson foi utilizado para a comparação da distorção entre as matrizes original e a cofenética considerando que o valor mínimo de 0,80 confere a fidelidade do dendrograma e quanto maior, menor é a distorção em relação à matriz original de dados (Valentin 2000).

Tabela 1. Caracterização ambiental do reservatório da UHE Mogi Guaçu e das lagoas marginais da fazenda Campininha.

Table 1. Environmental characterization of Mogi Guaçu hydroelectric dam and oxbow lakes from Campininha farm.

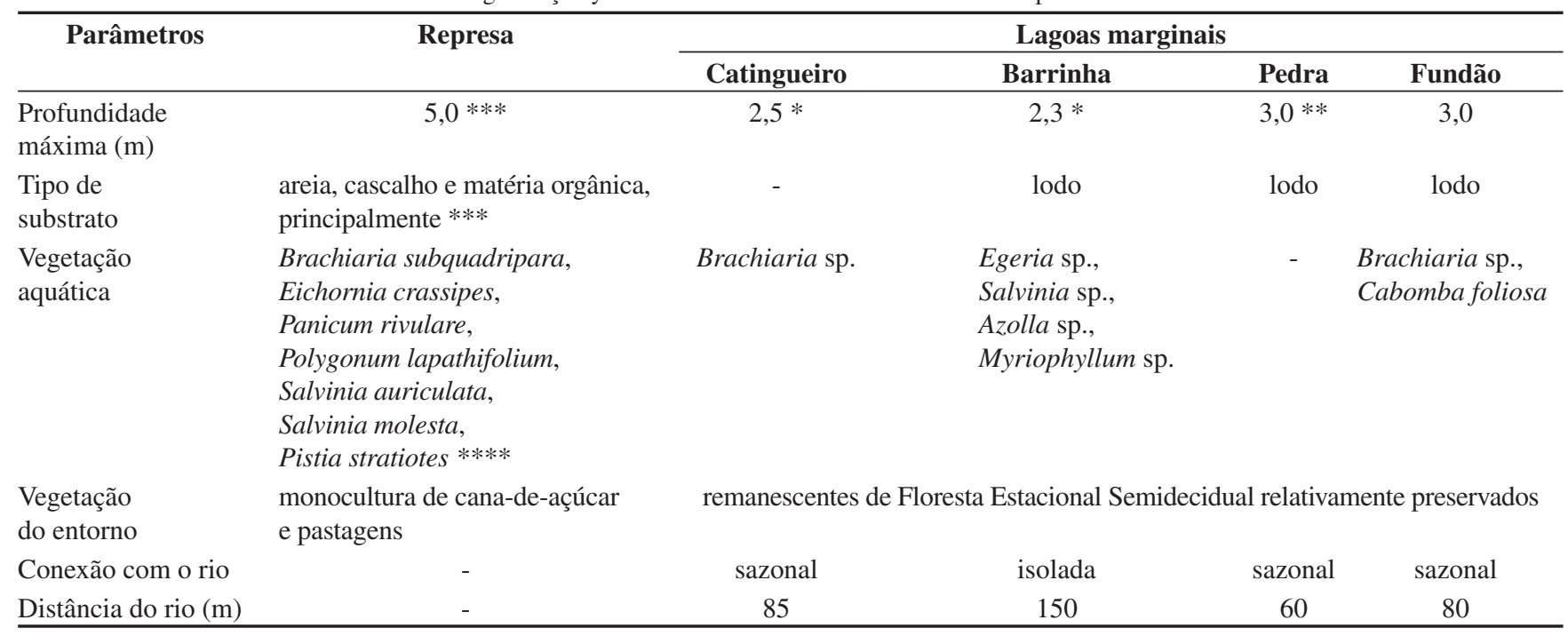

*segundo Esteves et al. (2000); **no período de cheia; ***segundo Brandimarte et al. (2005); ****segundo Cavenaghi et al. (2005). 
Foram feitas curvas de espécie-abundância para a represa e as lagoas marginais para verificar como as espécies estão distribuídas e indicar quais são as dominantes e raras nos ambientes (Magurran 2004). Para verificar os padrões de dominância em peso (biomassa) ou abundância das espécies em cada ambiente, foi utilizado o método baseado em curvas de k-dominância (curvas $\mathrm{ABC}$ ), utilizando os valores de abundância e biomassa cumulativos de cada espécie para cada amostra. A estatística W obtida informa a relação de dominância em peso quando é positiva e a dominância em número de indivíduos quando é negativa (Magurran 2004).

\section{Resultados}

De modo geral, durante o período de estudo a água das lagoas marginais esteve menos oxigenada e mais ácida do que a da represa (Tabela 2). Foram capturados 2.341 exemplares de 41 espécies pertencentes a cinco ordens e 15 famílias, perfazendo uma biomassa total de $85,8 \mathrm{~kg}$ (Tabela 3). A ordem Characiformes foi a que apresentou maior riqueza de espécies (61\%), seguida por Siluriformes (29\%), Gymnotiformes (5\%), Cyprinodontiformes (2,5\%) e Perciformes (2,5\%) (Figura 2). A família com o maior número de indivíduos (968 exemplares) e espécies (14) foi Characidae, representando 41,3\% das espécies capturadas. Cyphocharax modestus, Hyphessobrycon eques, Astyanax fasciatus, Steindachnerina insculpta, Astyanax altiparanae, Hyphessobrycon bifasciatus e Hoplosternum littorale foram as espécies mais abundantes $(607,379,175,171,144,111 \mathrm{e}$ 107 exemplares, respectivamente). Auchenipteridae e Callichthyidae foram famílias pouco representativas, com uma única espécie (Parauchenipterus galeatus e Callichthys callichthys, respectivamente) e apenas um exemplar coletado (Tabela 3). Ressalta-se que Phalloceros caudimaculatus foi coletado ocasionalmente na represa após o período de estudo, portanto, para este ambiente, foi excluído das análises, tendo sido apenas, registrado a sua ocorrência.

$\mathrm{Na}$ represa foram amostrados 1.368 exemplares pertencentes a quatro ordens, 12 famílias e 31 espécies, perfazendo uma biomassa total de $52,8 \mathrm{~kg}$ (Tabela 3). Nas lagoas marginais, foram capturados 973 exemplares pertencentes a cinco ordens, 11 famílias e 24 espécies, com uma biomassa total de $33 \mathrm{~kg}$ (Tabela 3). Curimatidae e Characidae foram as famílias mais numerosas na represa (774 exemplares) e nas lagoas marginais (574 exemplares), sendo Cyphocharax modestus (524 exemplares) e Hyphessobrycon eques (354 exemplares) as espécies mais abundantes dessas famílias, respectivamente (Tabela 3). Na represa houve um predomínio de espécies de ambientes lênticos (Cyphocharax modestus, Steindachnerina insculpta e Astyanax fasciatus) (Figura 3a) no período de estudo e, nas lagoas marginais, as espécies de pequeno porte (Hyphessobrycon eques, $H$. bifasciatus e Phalloceros caudimaculatus) foram as mais abundantes (Figura 3b).
Na represa, 14 espécies foram consideradas residentes ou constantes, seis acessórias e 11 acidentais, enquanto que nas lagoas marginais 17, quatro e três espécies tiveram essa classificação, respectivamente (Tabela 4). A observação da amplitude do comprimento padrão (mm) revelou que indivíduos jovens pertencentes a um maior número de espécies foram capturados nas lagoas marginais em relação ao reservatório, sendo eles: Astyanax altiparanae, A. fasciatus, Hoplerythrinus unitaeniatus, Prochilodus spp. e Hoplosternum littorale. Juvenis de Hoplias malabaricus e Geophagus brasiliensis ocorreram nos dois ambientes (Tabela 3).

A represa e as lagoas marginais apresentaram valores próximos de diversidade (H') e eqüitabilidade (E) de Shannon (Tabela 5). De modo geral, os maiores valores foram obtidos durante o período chuvoso e os menores durante o período seco, porém esta variação não foi suficiente para a ANOVA detectar diferenças significativas entre a represa e as lagoas marginais $(p=0,467)$ nem entre os perí$\operatorname{odos}(p=0,381)$, indicando que a diversidade de peixes não sofreu alterações ao longo dos meses de estudo (Tabela 6).

$\mathrm{O}$ dendrograma de similaridade, obtido conforme o índice de Morisita-Horn, separou as amostras em dois grupos distintos, revelando que a composição da ictiofauna de cada ambiente (represa e lagoas marginais) possui características pouco similares (Figura 4). Além disso, amostras referentes a um mesmo período, foram mais similares entre si, por exemplo, L5 e L6 (lagoas, período seco) e R2 e R3 (represa, período chuvoso).

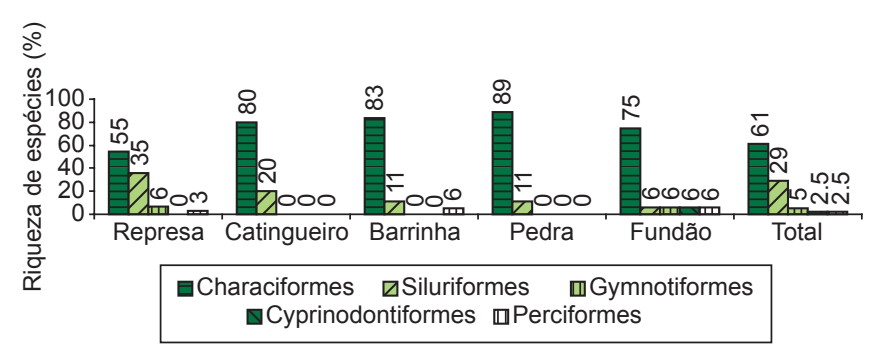

Figura 2. Composição percentual das ordens representativas da ictiofauna da UHE Mogi Guaçu (Characiformes, Siluriformes, Gymnotiformes e Perciformes) e das lagoas marginais da fazenda Campininha (Characiformes, Siluriformes, Gymnotiformes, Cyprinodontiformes e Perciformes), entre agosto de 2005 a julho de 2006.

Figure 2. Ichthyofauna orders percentage composition from Mogi Guaçu hydroelectric dam (Characiformes, Siluriformes, Gymnotiformes e Perciformes) and Campininha farm oxbow lakes (Characiformes, Siluriformes, Gymnotiformes, Cyprinodontiformes e Perciformes), during August 2005 to July 2006.

Tabela 2. Valores das variáveis físico-químicas da água registrados no reservatório da UHE Mogi Guaçu e lagoas marginais da fazenda Campininha, entre agosto de 2005 a julho de 2006.

Table 2. Values of physical and chemical variables of water recorded to Mogi Guaçu hydroelectric dam and oxbow lakes from Campininha farm, during August 2005 to July 2006.

\begin{tabular}{lccc}
\hline \multicolumn{1}{c}{ Locais } & Temperatura água $\left({ }^{\circ} \mathbf{C}\right)^{*}$ & $\mathbf{p H} * *$ & $\mathbf{O}_{\mathbf{2}}$ dissolvido $\left(\mathbf{m g . L ^ { - 1 }}\right)^{*}$ \\
\hline Represa & $21(17-24)$ & $6,6 \pm 0,2$ & $7,00(5,30-8,80)$ \\
Lagoa do Catingueiro & $17(13-24)$ & $5,2 \pm 0,3$ & $0,54(0,47-0,70)$ \\
Lagoa Barrinha & $19(10-27)$ & $5,6 \pm 0,1$ & $7,00(6,40-7,20)$ \\
Lagoa da Pedra & $19(12-24)$ & $5,5 \pm 0,2$ & $1,44(1,20-1,50)$ \\
Lagoa do Fundão & $21(15-26)$ & $5,8 \pm 0,1$ & $2,07(2,00-2,12)$ \\
\hline
\end{tabular}

*média (mínimo - máximo), **pH = média \pm desvio padrão 


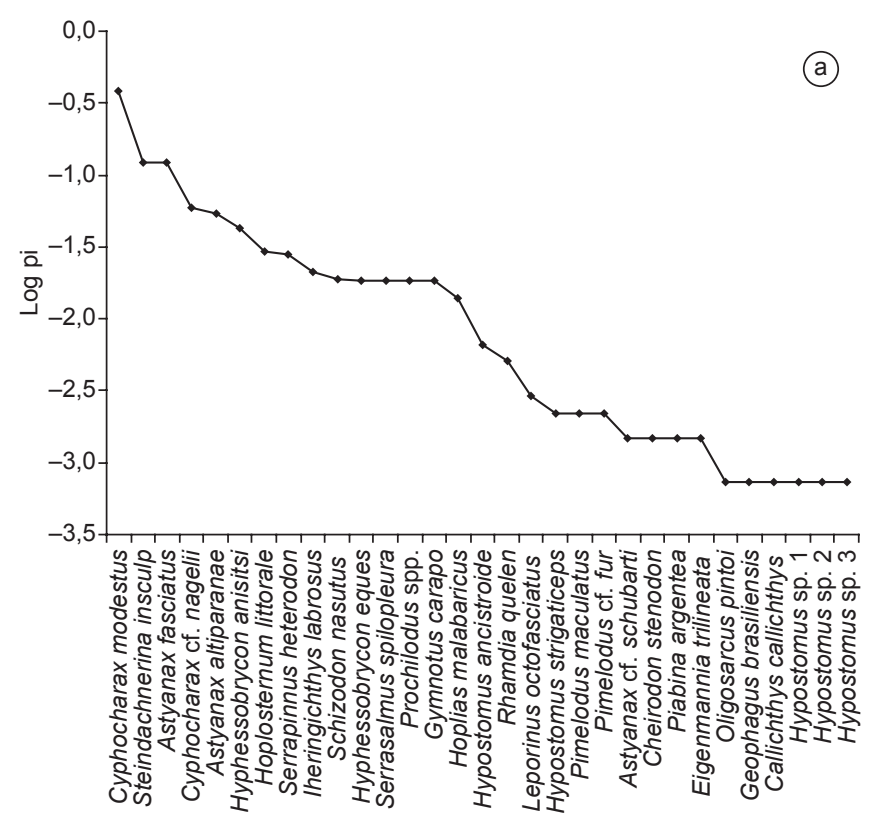

Seqüência de espécies

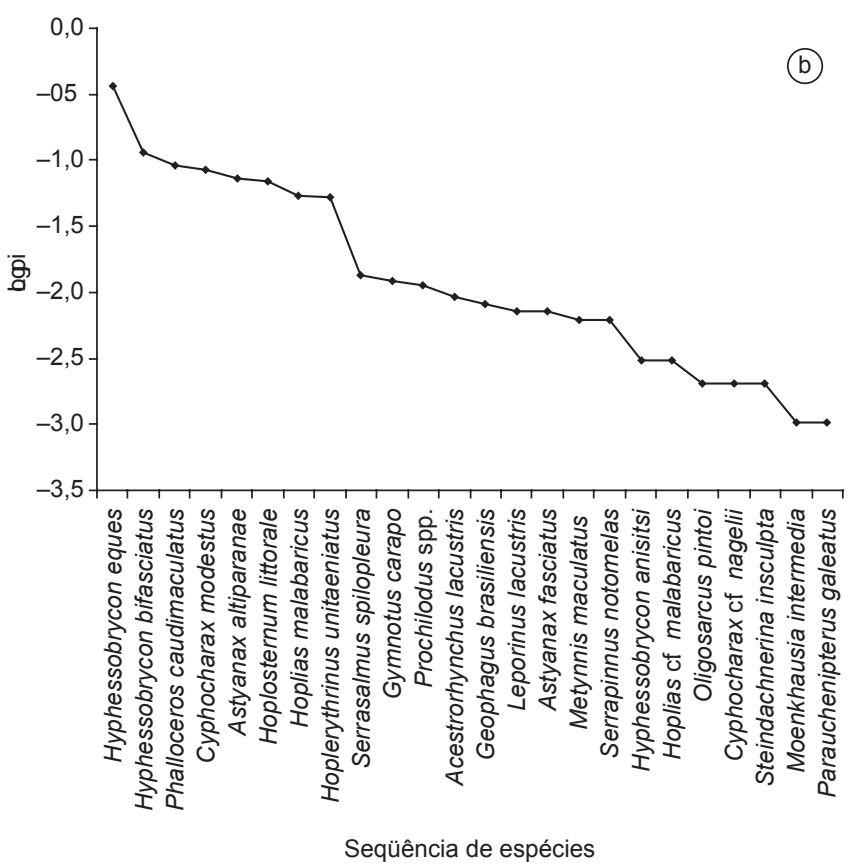

Figura 3. Curvas de espécie-abundância. a) reservatório da UHE Mogi Guaçu $\mathrm{e}, \mathrm{b})$ lagoas marginais da fazenda Campininha. $\mathrm{pi}=\mathrm{ni} / \mathrm{N}$, sendo $\mathrm{n}$ o número de exemplares das i espécies e $\mathrm{N}$ o número total de exemplares capturados para cada área.

Figure 3. Species-abundance curves. a) Mogi Guaçu hydroelectric dam and, b) Campininha farm oxbow lakes. $\mathrm{pi}=\mathrm{ni} / \mathrm{N}$, where $\mathrm{n}$ is the number of specimens from $\mathrm{i}$ species and $\mathrm{N}$ is the total number of collected specimens from each area.

As curvas $\mathrm{ABC}$ exibiram duas configurações. Na represa, a curva de abundância se posicionou acima da curva de biomassa $(\mathrm{W}<0)$ e nas lagoas marginais ocorreu o inverso, a curva de biomassa esteve posicionada acima da curva de abundância (W >0) (Figura 5).

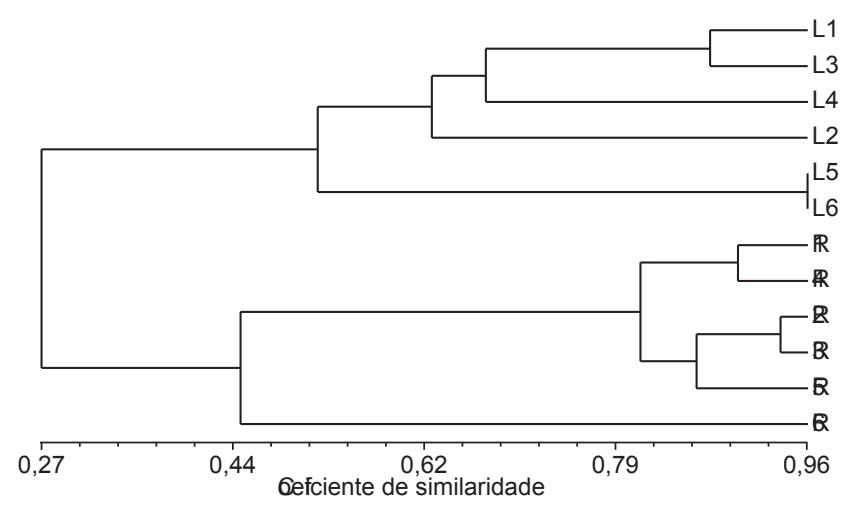

Figura 4. Dendrograma de similaridade ictiofaunística conforme o índice de Morisita-Horn (UPGMA) entre as amostras obtidas no reservatório da UHE Mogi Guaçu (R1 a R6) e nas lagoas marginais da fazenda Campininha (L1 a L6) entre agosto de 2005 a julho de 2006. Coeficiente de correlação cofenético: $r_{c}=0,89$.

Figure 4. Dendrogram obtained by Morisita-Horn index (UPGMA) representing the ichthyofauna similarity among reservoir samples (R1 to R6) and Campininha farm oxbow lakes (L1 to L6) during August 2005 to July 2006. Cophenetic correlation coefficient: $r_{c}=0.89$.
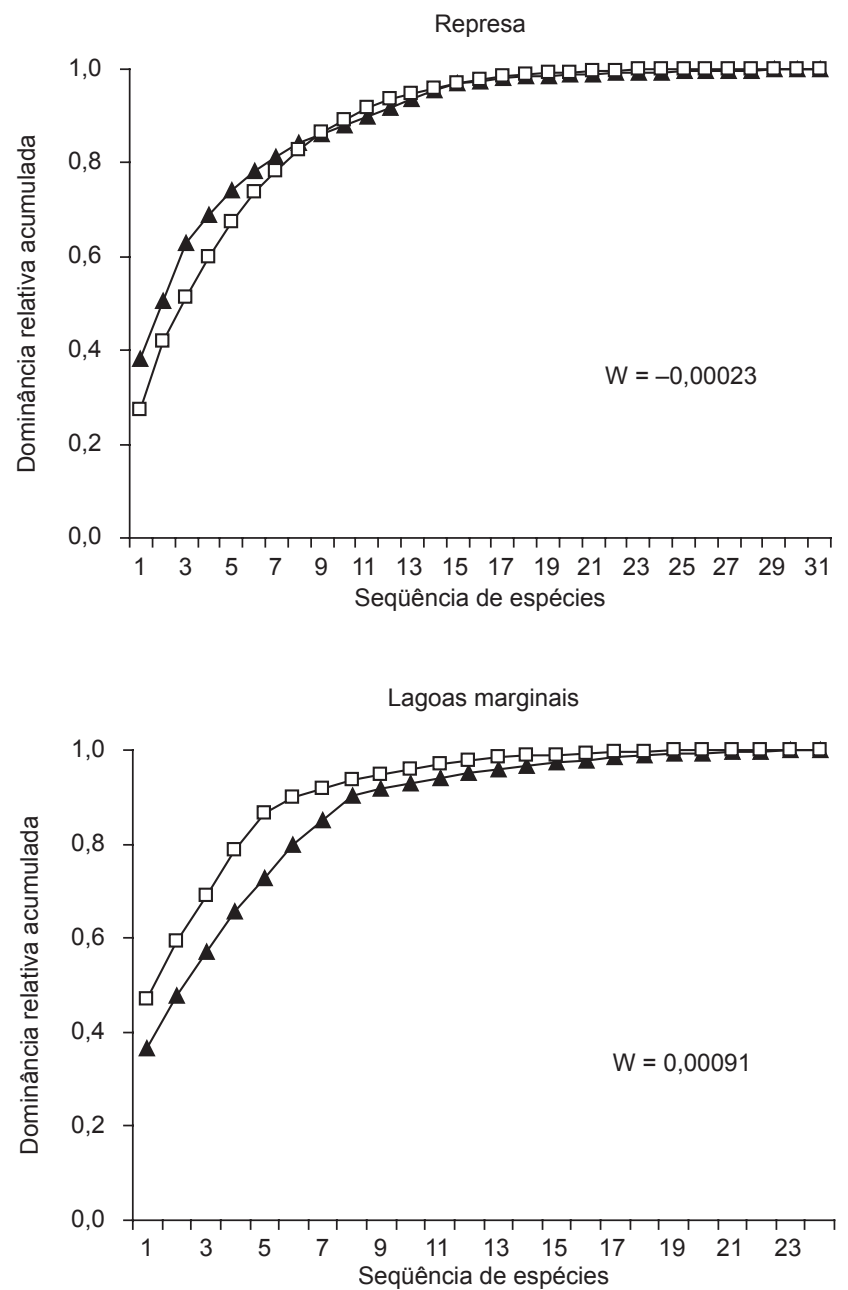

Figura 5. Curvas de abundância (triângulos) e biomassa (quadrados) para a represa e lagoas marginais.

Figure 5. Abundance (triangles) and biomass (squares) curves for reservoir and oxbow lakes. 
Tabela 3. Número total de exemplares coletados (N), amplitude do comprimento padrão (CP) em mm e biomassa total em kg dos peixes amostrados no reservatório da UHE Mogi Guaçu e lagoas marginais da fazenda Campininha, entre agosto de 2005 a julho de 2006 . S = riqueza de espécies.

Table 3. Number of collected specimens (N), standard length range (CP) in mm and total biomass in kg of the sampled fishes in Mogi Guaçu hydroelectric dam and oxbow lakes from Campininha farm, during August 2005 to July 2006. S = species richness.

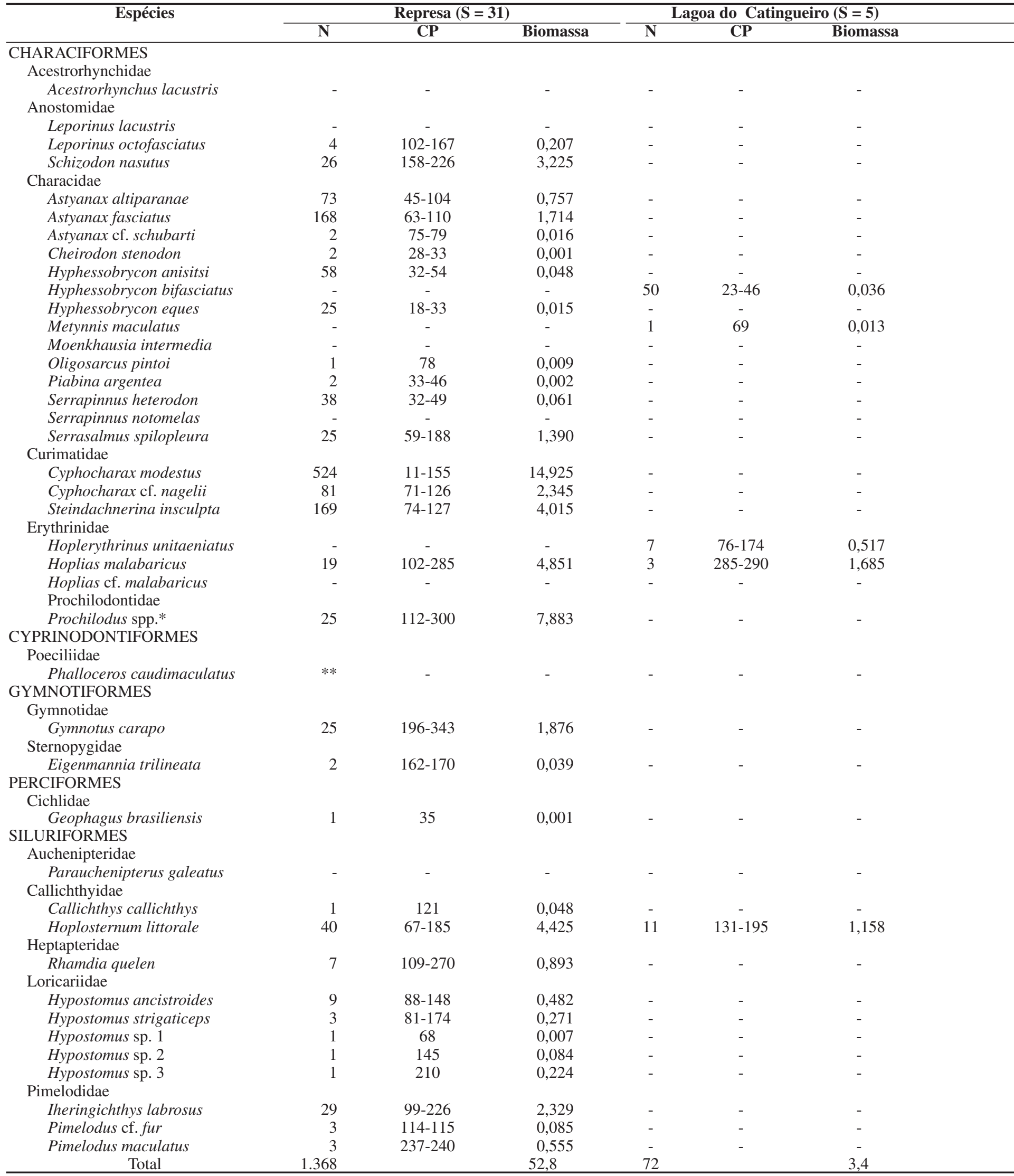

*Prochilodus spp. corresponde a P. lineatus e P. vimboides. **Phalloceros caudimaculatus ocorreu na represa, porém não foi quantificado. 


\begin{tabular}{|c|c|c|c|c|c|c|c|c|}
\hline \multicolumn{3}{|c|}{ Lagoa Barrinha ( $\mathrm{S}=18$ ) } & \multicolumn{3}{|c|}{ Lagoa da Pedra (S = 9) } & \multicolumn{3}{|c|}{ Lagoa do Fundão ( $(S=16)$} \\
\hline $\mathbf{N}$ & $\mathbf{C P}$ & Biomassa & $\mathbf{N}$ & $\mathbf{C P}$ & Biomassa & $\mathbf{N}$ & $\mathbf{C P}$ & Biomassa \\
\hline 9 & $136-184$ & 0,333 & - & - & - & - & - & - \\
\hline 7 & 105-169 & 0,482 & - & - & - & - & - & - \\
\hline- & - & - & - & - & - & - & - & - \\
\hline- & - & - & - & - & - & - & - & - \\
\hline 8 & $67-92$ & 0,107 & 26 & $24-51$ & 0,022 & 37 & $62-76$ & 0,111 \\
\hline - & - & - & 3 & $37-40$ & 0,004 & 4 & $75-78$ & 0,039 \\
\hline- & - & - & - & - & - & - & - & - \\
\hline- & - & - & - & - & - & - & - & - \\
\hline 2 & $32-36$ & 0,002 & - & - & - & 1 & 38 & 0,001 \\
\hline 14 & $32-41$ & 0,017 & 47 & $17-54$ & 0,032 & - & - & - \\
\hline 336 & $17-36$ & 0,209 & - & - & - & 18 & $27-37$ & 0,019 \\
\hline 5 & $52-83$ & 0,058 & - & - & - & - & - & - \\
\hline 1 & 13 & $<0,001$ & - & - & - & - & - & - \\
\hline 2 & 71-98 & 0,028 & - & - & - & - & - & - \\
\hline- & - & - & - & - & - & - & - & - \\
\hline - & - & - & - & - & - & - & - & - \\
\hline 4 & $15-19$ & 0,001 & 1 & 14 & $<0,001$ & 1 & 19 & $<0,001$ \\
\hline 9 & $54-129$ & 0,320 & - & - & - & 4 & $71-120$ & 0,133 \\
\hline 14 & $112-140$ & 0,734 & - & - & - & 69 & 80-137 & 2,657 \\
\hline - & - & - & - & - & - & 2 & $93-127$ & 0,076 \\
\hline - & - & - & - & - & - & 2 & $100-110$ & 0,052 \\
\hline 6 & $89-211$ & 0,509 & 23 & $97-197$ & 1,527 & 15 & $101-175$ & 0,730 \\
\hline 18 & $81-278$ & 2,590 & 25 & $140-284$ & 6,049 & 7 & $214-263$ & 2,123 \\
\hline 2 & $127-166$ & 0,140 & 1 & 106 & 0,028 & - & - & - \\
\hline - & - & - & 6 & 102-295 & 0,910 & 5 & $93-264$ & 1,124 \\
\hline- & - & - & - & - & - & 90 & $11-28$ & 0,009 \\
\hline - & - & - & - & - & - & 12 & $260-329$ & 0,930 \\
\hline - & - & - & - & - & - & - & - & - \\
\hline 7 & $24-145$ & 0,347 & - & - & - & 1 & 18 & $<0,001$ \\
\hline 1 & 120 & 0,050 & - & - & - & - & - & - \\
\hline- & - & - & - & - & - & - & - & - \\
\hline 1 & 98 & 0,034 & 19 & $120-280$ & 2,999 & 36 & $12-195$ & 4,003 \\
\hline
\end{tabular}


Tabela 4. Constância de ocorrência da ictiofauna no reservatório da UHE Mogi Guaçu e lagoas marginais da fazenda Campininha, entre agosto de 2005 a julho de 2006. $\mathrm{CO}=$ residente ou constante, $\mathrm{ACE}=$ acessória, $\mathrm{ACI}=$ acidental.

Table 4. Ichthyofauna constancy of occurrence to Mogi Guaçu hydroelectric dam and Campininha farm oxbow lakes, during August 2005 to July 2006. $\mathrm{CO}=$ resident or constant, $\mathrm{ACE}=$ accessory, $\mathrm{ACI}=$ accidental.

\begin{tabular}{|c|c|c|}
\hline Espécies & Represa & Lagoas marginais \\
\hline Acestrorhynchus lacustris & - & $\mathrm{ACE}$ \\
\hline Leporinus lacustris & - & $\mathrm{CO}$ \\
\hline Leporinus octofasciatus & $\mathrm{ACE}$ & - \\
\hline Schizodon nasutus & $\mathrm{CO}$ & - \\
\hline Astyanax altiparanae & $\mathrm{CO}$ & $\mathrm{CO}$ \\
\hline Astyanax fasciatus & $\mathrm{CO}$ & $\mathrm{CO}$ \\
\hline Astyanax cf. schubarti & $\mathrm{ACE}$ & - \\
\hline Cheirodon stenodon & $\mathrm{ACI}$ & - \\
\hline Hyphessobrycon bifasciatus & - & $\mathrm{CO}$ \\
\hline Hyphessobrycon anisitsi & ACI & $\mathrm{CO}$ \\
\hline Hyphessobrycon eques & $\mathrm{CO}$ & $\mathrm{CO}$ \\
\hline Metynnis maculatus & - & $\mathrm{CO}$ \\
\hline Moenkhausia intermedia & - & $\mathrm{ACI}$ \\
\hline Oligosarcus pintoi & $\mathrm{ACI}$ & $\mathrm{ACE}$ \\
\hline Piabina argentea & $\mathrm{ACI}$ & - \\
\hline Serrapinnus heterodon & $\mathrm{ACI}$ & - \\
\hline Serrapinnus notomelas & - & $\mathrm{ACI}$ \\
\hline Serrasalmus spilopleura & $\mathrm{CO}$ & $\mathrm{CO}$ \\
\hline Cyphocharax modestus & $\mathrm{CO}$ & $\mathrm{CO}$ \\
\hline Cyphocharax cf. nagelii & $\mathrm{CO}$ & $\mathrm{ACE}$ \\
\hline Steindachnerina insculpta & $\mathrm{CO}$ & $\mathrm{ACE}$ \\
\hline Hoplerythrinus unitaeniatus & - & $\mathrm{CO}$ \\
\hline Hoplias malabaricus & $\mathrm{CO}$ & $\mathrm{CO}$ \\
\hline Hoplias cf. malabaricus & - & $\mathrm{CO}$ \\
\hline Prochilodus spp. & $\mathrm{CO}$ & $\mathrm{CO}$ \\
\hline Phalloceros caudimaculatus & - & $\mathrm{CO}$ \\
\hline Gymnotus carapo & $\mathrm{CO}$ & $\mathrm{CO}$ \\
\hline Eigenmannia trilineata & $\mathrm{ACI}$ & - \\
\hline Geophagus brasiliensis & $\mathrm{ACI}$ & $\mathrm{CO}$ \\
\hline Parauchenipterus galeatus & - & $\mathrm{ACI}$ \\
\hline Callichthys callichthys & $\mathrm{ACI}$ & - \\
\hline Hoplosternum littorale & $\mathrm{CO}$ & $\mathrm{CO}$ \\
\hline Rhamdia quelen & $\mathrm{CO}$ & - \\
\hline Hypostomus ancistroides & $\mathrm{ACE}$ & - \\
\hline Hypostomus strigaticeps & $\mathrm{ACE}$ & - \\
\hline Hypostomus sp. 1 & $\mathrm{ACI}$ & - \\
\hline Hypostomus sp. 2 & $\mathrm{ACI}$ & - \\
\hline Hypostomus sp. 3 & $\mathrm{ACI}$ & - \\
\hline Iheringichthys labrosus & $\mathrm{CO}$ & - \\
\hline Pimelodus maculatus & $\mathrm{ACE}$ & - \\
\hline \multirow[t]{2}{*}{ Pimelodus cf. fur } & $\mathrm{ACE}$ & - \\
\hline & $\mathrm{CO}=45 \%$ & $\mathrm{CO}=71 \%$ \\
\hline \multirow[t]{2}{*}{ Total } & $\mathrm{ACE}=19 \%$ & $\mathrm{ACE}=17 \%$ \\
\hline & $\mathrm{ACI}=36 \%$ & $\mathrm{ACI}=12 \%$ \\
\hline
\end{tabular}

Tabela 5. Índices de diversidade (H') e eqüitabilidade (E) de Shannon para cada amostra (mês) no reservatório da UHE Mogi Guaçu e lagoas marginais da fazenda Campininha.

Table 5. Shannon's diversity index (H') and evenness (E) to each sample (month) to Mogi Guaçu hydroelectric dam and Campininha farm oxbow lakes.

\begin{tabular}{cccccc}
\hline \multirow{2}{*}{ Amostras } & \multicolumn{3}{c}{$\mathbf{H}^{\prime}$} & & \multicolumn{2}{c}{$\mathbf{E}$} \\
\cline { 2 - 3 } \cline { 5 - 6 } & Represa & $\begin{array}{c}\text { Lagoas } \\
\text { marginais }\end{array}$ & & Represa & $\begin{array}{c}\text { Lagoas } \\
\text { marginais }\end{array}$ \\
\hline 1 & 0,637 & 0,884 & & 0,427 & 0,640 \\
2 & 0,944 & 1,001 & & 0,633 & 0,725 \\
3 & 1,013 & 0,710 & & 0,679 & 0,514 \\
4 & 0,897 & 1,041 & & 0,601 & 0,754 \\
5 & 1,139 & 0,769 & & 0,764 & 0,557 \\
6 & 0,930 & 0,723 & & 0,624 & 0,524 \\
\hline
\end{tabular}

Tabela 6. Resultado da análise de variância (ANOVA two-way) para o índice de Shannon, considerando o local de coleta (represa e lagoas marginais) e o período do ano (meses).

Table 6. Variance analysis results (two-way ANOVA) to Shannon index, considering the sample site (reservoir and oxbow lakes) and the seasons (months).

\begin{tabular}{lccccc}
\hline $\begin{array}{c}\text { Fonte de } \\
\text { variação }\end{array}$ & $\begin{array}{c}\text { Soma dos } \\
\text { Quadrados }\end{array}$ & gL & $\begin{array}{c}\text { Quadrado } \\
\text { Médio }\end{array}$ & F & P \\
\hline Local & 0,016 & 1 & 0,016 & 0,584 & 0,467 \\
Período & 0,023 & 1 & 0,023 & 0,859 & 0,381 \\
Local * Período & 0,004 & 1 & 0,004 & 0,163 & 0,697 \\
Resíduo & 0,213 & 8 & 0,027 & - & - \\
\hline
\end{tabular}

\section{Discussão}

A composição da ictiofauna na represa e nas lagoas marginais mostrou elevada riqueza de espécies pertencentes às ordens Characiformes e Siluriformes (somando $90 \%$ da riqueza total) e pela presença de Gymnotiformes, Cyprinodontiformes e Perciformes, concordando com o padrão geral esperado para ambientes neotropicais de água doce (Lowe-McConnell 1999). Segundo Agostinho et al. (2007), apesar de essas ordens serem dominantes em todas as bacias sulamericanas, a composição específica e o número de espécies entre bacias varia muito.

No reservatório da UHE Mogi Guaçu foram capturadas 31 espécies de peixes e nas lagoas marginais da fazenda Campininha, 24 espécies. Com este estudo, foram acrescentadas 16 espécies às oito citadas por Esteves et al. (2000) nestas mesmas lagoas. O aumento do número de espécies amostradas certamente resultou do maior esforço empregado juntamente com o auxílio de diferentes apetrechos de pesca. Schizodon nasutus foi a única espécie capturada por Esteves et al. (2000) que não apareceu em nossas coletas nas lagoas marginais. Agostinho et al. (2007) analisando dados provenientes de 77 reservatórios brasileiros, observaram que $85 \%$ deles apresentaram uma riqueza total inferior a 40 espécies de peixes, o que representa um número relativamente baixo em comparação ao tamanho das áreas alagadas de reservatórios de UHEs. Esses mesmos autores também perceberam que lagoas marginais com áreas inferiores a $0,2 \mathrm{~km}^{2}$ chegaram a apresentar até 30 espécies. Muitas variáveis podem ser determinantes para o número de espécies em reservatórios, porém sabe-se que a diversidade diminui com o tempo, assim que as espécies 
começam a se estabilizar no novo ambiente (Castro \& Arcifa 1987, Smith et al. 2002) e que em reservatórios recém formados, é esperado um maior número de espécies (Agostinho et al. 2007), o que não se aplica ao reservatório da UHE Mogi Guaçu, que possui 13 anos.

A ictiofauna residente dos ambientes estudados foi composta por peixes típicos da bacia do alto rio Paraná, indicando uma condição que, embora alterada pela construção da UHE, apresenta espécies essencialmente nativas desta região (exceto Hoplerythrinus unitaeniatus e Metynnis maculatus) (Langeani et al. 2007). Muitos trabalhos realizados na bacia do alto Paraná têm apontado o predomínio de espécies e a abundância de indivíduos das famílias Characidae (Ferreira et al. 2000, Perez Jr. \& Garavello 2007, Oliveira \& Garavello 2003) e Curimatidae (Castro \& Arcifa 1987, Smith et al. 2002, Crippa \& Hahn 2006, Petesse 2007). Na represa, o sagüiru Cyphocharax modestus (Curimatidae) foi a espécie mais abundante, seguida por Steindachnerina insculpta (Curimatidae) e Astyanax fasciatus (Characidae). Essas espécies geralmente predominam em ambientes lênticos represados (Castro \& Arcifa 1987, Smith et al. 2003), principalmente nas regiões litorâneas, sendo pré-ajustadas para viverem nesses ambientes alterados pelo homem (Smith et al. 2003, Agostinho et al. 2007). Segundo Benedito-Cecílio \& Agostinho (1997), essas espécies de pequeno porte podem ser classificadas como oportunistas por possuírem características sedentárias, alto potencial reprodutivo, plasticidade trófica, baixa longevidade e ampla tolerância a adversidades ambientais, exibindo maior facilidade na colonização desses ambientes.

Nas lagoas marginais, as espécies de pequeno porte predominaram em número no período de estudo, principalmente Hyphessobrycon bifasciatus, H. eques, Phalloceros caudimaculatus e Cyphocharax modestus. Essa predominância poderia estar associada à presença abundante de macrófitas aquáticas, que oferecem locais ideais para forrageamento (Esteves 1996, Esteves et al. 2000, Meschiatti et al. 2000, Casatti et al. 2003, Pelicice \& Agostinho 2006) e abrigo contra predadores (Smith \& Barrella 2000), além de fornecerem oxigênio através de suas raízes (Jedicke et al. 1989, Sánchez-Botero et al. 2003) e de constituírem micro-hábitats lênticos pouco profundos que propiciam condições favoráveis para o estabelecimento destas espécies (Ferreira et al. 2000). Além disso, a composição da ictiofauna em lagoas marginais pode estar relacionada ao tamanho do ambiente (Galetti Jr. et al. 1990).

As curvas ABC devem ser interpretadas levando-se em consideração as estratégias r-k das espécies (Magurran 2004). Em ambientes relativamente estáveis, a curva de biomassa se localiza acima da curva de abundância numérica, indicando a dominância de espécies teoricamente do tipo k-estrategistas de maior porte e ciclo de vida longo. Normalmente estão representadas por poucas espécies, porém em termos de biomassa são dominantes no ambiente (Casatti et al. 2006). No presente estudo, as lagoas marginais apresentaram uma comunidade com esse padrão, onde as espécies Hoplias malabaricus, Hoplerythrinus unitaeniatus, Hoplosternum littorale e Prochilodus spp. tiveram maior contribuição na biomassa total deste ambiente. A abundância de Hoplias malabaricus e Hoplerythrinus unitaeniatus pode estar relacionada com a disponibilidade de presas (Hyphessobrycon bifasciatus e H. eques), visto que foram itens alimentares frequientes no conteúdo estomacal destas espécies nas lagoas marginais da fazenda Campininha durante este estudo (Gonçalves 2007). Clarke \& Warwick (1994) apud Casatti et al. (2006), apontam que a presença de uma guilda de predadores posiciona a curva de biomassa acima da curva de abundância .

Na represa, a curva de abundância se posicionou acima da curva de biomassa, indicando que espécies com tendências r-estrategistas de menor porte e ciclo de vida curto foram numericamente dominantes, como Cyphocharax modestus, Steindachnerina insculpta, Astyanax fasciatus, C. cf. nagelii e A. altiparanae, refletindo um ambiente sob maior influência antrópica. O caráter oportunista destas espécies de caracídeos e curimatídeos, que favorece seu estabelecimento em ambientes alterados, tem sido amplamente documentado na literatura conforme discutido anteriormente. Na represa de Barra Bonita (Petesse et al. 2007), no reservatório de Jurumirim (Carvalho \& Silva 1999) e de Segredo (Penczak \& Agostinho 1997) resultados semelhantes foram registrados, com dominância de espécies de pequeno e médio porte, caracterizando uma comunidade moderadamente perturbada, típica de reservatórios.

Assim como verificado por Esteves et al. (2000), as lagoas marginais da fazenda Campininha apresentaram principalmente espécies de ambientes lênticos, com a presença de poucas espécies reofílicas. Também foram encontrados juvenis de muitas espécies neste ambiente: Astyanax altiparanae, A. fasciatus, Hoplerythrinus unitaeniatus, Prochilodus spp., Hoplosternum littorale, Hoplias malabaricus e Geophagus brasiliensis. Esse resultado parece indicar que, para algumas espécies, essas lagoas marginais podem ainda estar desempenhando a função de berçários naturais, oferecendo abrigo e alimento para jovens de espécies de médio porte (como Prochilodus spp.) que utilizam esses ambientes para seu desenvolvimento inicial (Galetti Jr. et al. 1990, Agostinho et al. 1997a, Meschiatti 1998, Esteves et al. 2000, Smith et al. 2003).

De todas as variáveis físico-químicas da água, a concentração de oxigênio dissolvido pode ter sido o que mais influenciou a composição da ictiofauna nas lagoas marginais do presente estudo. De acordo com Lowe-McConnell (1999), lagoas marginais muitas vezes apresentam condições de oxigenação e temperatura estressantes para muitas espécies de peixes. Espécies mais tolerantes e que exibem adaptações respiratórias conseguem permanecer nestes ambientes. Hoplias malabaricus e Hoplerythrinus unitaeniatus, residentes nas lagoas marginais da fazenda Campininha, possuem adaptações morfofisiológicas no aparato respiratório que conferem alta tolerância a ambientes hipóxicos, assim como Hoplosternum littorale (Dickson \& Grahan 1986, Jucá-Chagas 2004, Jucá-Chagas \& Boccardo 2006) que, como os demais membros da família Callichthyidae, utiliza obrigatoriamente ar atmosférico na respiração (Reis 2003). Ainda, Gymnotus carapo e Parauchenipterus galeatus foram espécies presentes nas lagoas marginais que também toleram águas com baixas concentrações de oxigênio dissolvido. Assim, presume-se que essas espécies tenham sido abundantes nas lagoas marginais (exceto P. galeatus), visto que são ambientes com condições ambientais propícias.

As curvas de espécie-abundância mostraram ser um método adequado para descrever a relação entre as espécies e o número de indivíduos, ou seja, uma comunidade com um número expressivo de espécies raras (acidentais e acessórias) e poucas dominantes (residentes ou constantes), assim como observado em outros reservatórios de UHEs (Benedito-Cecilio \& Agostinho 2000, Castro et al. 2003, Oliveira et al. 2003, Hoffmann et al. 2005, Britto \& Carvalho 2006, Silva et al. 2006, Petesse et al. 2007), lagoas marginais (Meschiatti et al. 2000, Oliveira et al. 2001, Cunico et al. 2002, Okada et al. 2003, Petry et al. 2003) e outros ambientes (Casatti 2005, Mendonça et al. 2005, Ferreira 2007). Geralmente, as espécies residentes são também as mais abundantes em um ambiente (Agostinho et al. 1997b), padrão igualmente verificado no presente estudo.

Não foi possível inferir nenhuma modificação na estrutura da comunidade através dos índices de diversidade e eqüitabilidade de Shannon por terem se comportado de maneira semelhante tanto na represa quanto nas lagoas. Esses índices desconsideram a identidade das espécies no seu cálculo, sendo insensíveis às diferenças que existem na composição da ictiofauna entre a represa e as lagoas marginais. Assim, a interpretação destes resultados deve ser feita com cautela levando em consideração o papel ecológico de cada espécie 
no ambiente. Outros trabalhos também apontaram a ausência de sazonalidade na estruturação da comunidade de peixes em represas, como Silva et al. (2006) e Petesse (2007). Além disso, a maioria dos estudos que abordam a estrutura da ictiofauna investiga a diversidade entre as diferentes zonas (fluvial, de transição e lêntica) que compõem o reservatório (Benedito-Cecilio \& Agostinho 2000, Araújo \& Santos 2001, Oliveira et al. 2003, Britto \& Carvalho 2006, Souza-Hojo 2008) e não as variações temporais. Dessa forma, geralmente encontram maior diversidade em pontos distantes da barragem com características lóticas que abrangem a zona fluvial (tributários) e de transição do que no ambiente lêntico próximo à barragem (Hoffmann et al. 2005, Britto \& Carvalho 2006, Petesse 2007).

A ausência de sazonalidade nas comunidades de peixes no sistema de lagoas marginais da planície de inundação da fazenda Campininha pode estar sendo influenciada pela presença da UHE Mogi Guaçu, localizada cerca de $43 \mathrm{~km}$ a montante. Barramentos alteram o regime natural de vazão do rio, modificando o sistema de pulso de inundação da planície (Agostinho et al. 2004a), com reflexos na ictiofauna (Agostinho et al. 2004b, Gubiani et al. 2007, Novakowski et al. 2007). Como as variações temporais dos fatores biológicos estão intimamente relacionadas com o sistema de inundação rio-planície (Junk et al. 1989, Agostinho et al. 2004a), é de se esperar que a regulação artificial da vazão do rio pela UHE Mogi Guaçu esteja influenciando a diversidade de peixes das lagoas marginais da fazenda Campininha. Além disso, Esteves et al. (2000) sugeriram que o aprofundamento da calha do rio causado pela extração de areia em pontos próximos das lagoas marginais da fazenda Campininha poderia estar influenciando o regime de inundação na planície, dificultando a ocorrência dos transbordamentos laterais.

Apesar dos impactos causados, a regulação da hidrografia da planície torna-se previsível pela operação de UHEs, permitindo um manejo do fluxo de água a fim de manter o mais próximo do regime natural e diminuir os impactos à ictiofauna (Agostinho et al. 2004a). Dessa forma, o procedimento operacional adequado da UHE Mogi Guaçu torna-se imprescindível para a manutenção da diversidade da fauna de peixes e a integridade das lagoas marginais da fazenda Campininha, assim como constatado por Agostinho et al. (2001) na planície de inundação do alto rio Paraná.

Apesar dos índices de diversidade e eqüitabilidade de Shannon não terem evidenciado as diferenças na composição da ictiofauna entre os ambientes estudados, a análise de similaridade pelo índice de Morisita-Horn apontou que a ictiofauna da represa e das lagoas marginais apresentam baixa similaridade entre si. A análise de similaridade entre as amostras resultou em um dendrograma com dois grupos distintos, um compreendendo a represa e outro as lagoas marginais, em que amostras referentes ao mesmo período apresentaram distâncias menores, assim como registrado por Araújo \& Santos (2001) e Silva et al. (2007). Dessa forma, constata-se que a ictiofauna destes dois ambientes são pouco similares.

Por fim, sugere-se que a extração de areia no leito do rio, aliado ao controle da vazão pela UHE Mogi Guaçu a montante, interfere negativamente no equilíbrio e manutenção da planície de inundação do rio Mogi Guaçu na área de entorno da fazenda Campininha. Estudos que enfoquem essas fontes de impactos devem ser conduzidos, para que futuras decisões de manejo sejam tomadas visando à conservação desses ambientes naturais e de sua ictiofauna.

\section{Agradecimentos}

A autora agradece P. Rubim, G. Rubim, os pescadores "Toninho" e "Lei”, J. Lourenço, U. P. Souza, D. F. de Oliveira e T. Moraes pelo auxílio no campo e/ou laboratório; F. C. Ferreira pela ajuda durante a análise dos dados; diretor J. A. Freitas e funcionários da Estação
Ecológica Mogi Guaçu pelo apoio; F. Langeani e N. S. Hahn pela análise crítica da dissertação de mestrado; J. C. Garavello e F. Langeani pela identificação dos peixes; aos assessores anônimos pelas críticas e sugestões; ao IBAMA (02027.000991/2005-71); à COTEC (42.042/2005) e à CAPES pela bolsa de estudo (C.S.G.). Este manuscrito faz parte da dissertação de mestrado de C.S.G. pelo Programa de Zoologia da UNESP, Rio Claro,SP.

\section{Referências Bibliográficas}

AES-TIETÊ. http://www.aes-tiete.com.br (último acesso em 14/10/2007). AGOStinho, A.A., JÚliO Jr., H.F., GOMES, L.C., BINI, L.M. \& AGOSTINHO, C.S. 1997a. Composição, abundância e distribuição espaço-temporal da ictiofauna. In A planície de inundação do alto rio Paraná (A.E.A.M. Vazzoler, A.A. Agostinho \& N.S. Hahn, orgs.). EDUEM, Maringá, p. 179-208.

AGOStinho, A.A., BINI, L.M. \& GOMES, L.C. 1997b. Ecologia de comunidades de peixes da área de influência do reservatório de Segredo. In Reservatório de Segredo: bases ecológicas para o manejo (A.A. Agostinho \& L.C. Gomes, orgs.). EDUEM, Maringá, p. 97-111.

AGOSTINHO, A.A., GOMES, L.C. \& ZALEWSKI, M. 2001. The importance of floodplains for the dynamics of fish communities of the upper River Paraná. Ecohydrol. \& Hydrobiol. 1(1-2): 209-217.

AGOSTINHO, A.A., GOMES, L.C., VERÍSSIMO, S. \& OKADA, E.K. 2004a. Flood regime, dam regulation and fish in the Upper Paraná River: effects on assemblage attributes, reproduction and recruitment. Rev. Fish. Biol. Fish. 14: 11-19.

AGOSTINHO, A.A., THOMAZ, S.M. \& GOMES, L.C. 2004b. Threats for biodiversity in the floodplain of the Upper Paraná River: effects of hydrological regulation by dams. Ecohydrol. \& Hydrobiol. 4(3): 255-268.

AGOSTINHO, A.A., THOMAZ, S.M. \& GOMES, L.C. 2005. Conservação da biodiversidade em águas continentais do Brasil. Megadiversidade 1(1): 70-78

AGOSTINHO, A.A., GOMES, L.C. \& PELICICE, F.M. 2007. Ecologia e manejo de recursos pesqueiros em reservatórios do Brasil. EDUEM, Maringá.

ARAÚJO, F.G. \& SANTOS, L.N. 2001. Distribution of fish assemblages in Lajes reservoir, Rio de Janeiro, Brasil. Braz. J. Biol. 61(4): 563-576.

BARBIERI, G., SALLES, F.A. \& CESTAROLLI, M.A. 2000. Análise populacional do curimbatá, Prochilodus lineatus, do rio Mogi Guaçu, Pirassununga, SP (Characiformes, Prochilodontidae). B. Inst. Pesca 26(2): 137-145.

BENEDITO-CECILIO, E. \& AGOSTINHO, A.A. 1997. Estrutura das populações de peixes no reservatório de Segredo. In Reservatório de Segredo: bases ecológicas para o manejo (A.A. Agostinho \& L.C. Gomes, orgs.). EDUEM, Maringá, p. 113-139.

BENEDITO-CECILIO, E. \& AGOSTINHO, A.A. 2000. Distribution, abundance and use of different environments by dominant ichthyofauna in the influence area of the Itaipu reservoir. Acta Sci. Biol. Sci. 22(2): 429-437.

BRANDIMARTE, A.L., ANAYA, M. \& SHIMIZU, G.Y. 2005. Downstream impact of Mogi-Guaçu River damming on the benthic invertebrates (São Paulo State, Brazil). Acta Limnol. Bras. 17(1): 27-36.

BRIGANTE, J. \& ESPÍNDOLA, E.L.G. 2003. A bacia hidrográfica: aspectos conceituais e caracterização geral da bacia do rio Mogi-Guaçu. In Limnologia fluvial: um estudo no rio Mogi-Guaçu (J. Brigante \& E.L.G. Espíndola, eds.). RIMA, São Carlos, p. 1-13.

BRITSKI, H., SILIMON, K.Z.S. \& LOPES, B.S. 1999. Peixes do Pantanal: manual de identificação. Embrapa, Brasília.

BRITTO, S.G.C. \& CARVALHO, E.D. 2006. Ecological attributes of fish fauna in the Taquaruçu reservoir, Paranapanema river (upper Paraná, Brazil): composition and spatial distribution. Acta Limnol. Bras. 18(4): 377-388. 
CARVALHO, E.D. \& SILVA, V.F.B. 1999. Aspectos ecológicos da ictiofauna e da produção pesqueira do reservatório de Jurumirim (alto rio Paranapanema, São Paulo). In Ecologia de reservatórios: estrutura, função a aspectos sociais (R Henry, ed.). Fapesp, São Paulo, 95-109.

CASATTI, L., MENDES, H.F. \& FERREIRA, K.M. 2003. Aquatic macrophytes as feeding site for small fishes in the Rosana reservoir, Paranapanema river, southeastern Brazil. Braz. J. Biol. 63(2): 213-222.

CASATTI, L., LANGEANI, F. \& FERREIRA, C.P. 2006. Effects of physical habitat degradation on the stream fish assemblage structure in a pasture region. Environ. Manage. 38(6): 974-982.

CASATTI, L. 2005. Fish assemblage structure in a first order stream, southeastern Brazil: longitudinal distribution, seasonality, and microhabitat diversity. Biota Neotrop. 5(1): http://www.biotaneotropica. org.br/v5n1/pt/abstract?article+BN02505012005 (último acesso em 07/03/2008).

CASTRO, R.J., FORESTI, F. \& CARVALHO, E.D. 2003. Composição e abundância da ictiofauna na zona litorânea de um tributário, na zona de sua desembocadura no reservatório de Jurumirim, estado de São Paulo, Brasil. Acta Sci. Biol. Sci. 25(1): 63-70.

CASTRO, R.M.C. \& ARCIFA, M.S. 1987. Comunidades de peixes de reservatórios no sul do Brasil. Rev. Brasil. Biol. 47(4): 493-500.

CAVENAGHI, A.L., VELINI, E.D., NEGRISOLI, E., CARVALHO, F.T., GALO, M.L.B.T., TRINDADE, M.L.B., CORRÊA, M.R. \& SANTOS, S.C.A. 2005. Monitoramento de problemas com plantas aquáticas e caracterização da qualidade de água e sedimento na UHE Mogi-Guaçu. Planta Daninha 23(2): 225-231

CBH-Mogi (Comitê da bacia hidrográfica do rio Mogi Guaçu). 1999. Diagnóstico da bacia hidrográfica do rio Mogi Guaçu: Relatório Zero. Mogi Guaçu.

CRIPPA, V.E.L. \& HAHN, N.S. 2006. Use of food resources by the fish fauna of a small reservoir (rio Jordão, Brazil) before and shortly after its filling. Neotrop. Ichthyol. 4(3): 357-362.

CUNICO, A.M., GRAÇA, W.J., VERÍSSIMO, S. \& BINI, L.M. 2002. Influência do nível hidrológico sobre a assembléia de peixes em lagoa sazonalmente isolada da planície de inundação do alto rio Paraná. Acta Sci. Biol. Sci. 24(2): 383-389.

DAJOZ, R. 1972. Ecologia geral. Vozes, São Paulo.

DICKSON, K.A. \& GRAHAM, J.B. 1986. Adaptations to hypoxic environments in the erythrinid fish Hoplias microlepis. Environ. Biol. Fish. 15(4): 301-308.

ESTEVES, K.E. 1996. Feeding ecology of three Astyanax species (Characidae, Tetragonopterinae) from a floodplain lake of Mogi-Guaçú river, Paraná river basin, Brazil. Environ. Biol. Fish. 46(1): 83-101.

ESTEVES, K.E., SENDACZ, S., LÔBO, A.V.P. \& XAVIER, M.B. 2000. Características físicas, químicas e biológicas de três lagoas marginais do rio Mogi Guaçu (SP) e avaliação do seu papel como viveiro natural de espécies de peixes reofílicos. B. Inst. Pesca 26(2): 169-180.

FERREIRA, K.M. 2007. Biology and ecomorphology of stream fishes from the rio Mogi-Guaçu basin, southeastern Brazil. Neotrop. Ichthyol. 5(3): 311-326.

FERREIRA, A.G., VERANI, J.R., PERET, A.C. \& CASTRO, P.F. 2000. Caracterização de comunidades ícticas de lagoas marginais do rio Mogi Guaçu: composição, abundância e biomassa de peixes. In Estudos integrados em ecossistema: Estação Ecológica de Jataí (J.E. dos Santos \& J.S.R. Pires, eds). RIMA, São Carlos, p. 791-804.

GALETTI Jr., P.M., ESTEVES, K.E., LIMA, N.R.W., MESTRINER, C.A., CAVALlinI, M.M., CESAR, A.C.G. \& MIYAZAWA, C.S. 1990. Aspectos comparativos da ictiofauna de duas lagoas marginais do rio Mogi Guaçu (Alto Paraná - Estação Ecológica do Jataí, SP). Acta Limnol. Bras. 3(2): 865-885.

GODOY, M.P. 1975. Peixes do Brasil - subordem Characoidei, bacia do rio Mogi Guassu. Franciscana, São Paulo.

GONÇALVES, C.S. 2007. Biologia alimentar da ictiofauna na área de influência do reservatório da usina Mogi Guaçu e lagoas marginais da
Estação Ecológica - Fazenda Campininha (SP). Dissertação de mestrado, Universidade Estadual Paulista, Rio Claro.

GUBIANI, E.A., GOMES, L.C., AGOSTINHO, A.A. \& OKADA, E.K. 2007. Persistence of fish populations in the upper Paraná River: effects of water regulation by dams. Ecol. Fresh. Fish 16(2): 191-197.

HOFFMANN, A.C., ORSI, M.L. \& SHIBATTA, O.A. 2005. Diversidade de peixes do reservatório da UHE Escola Engenharia Mackenzie (Capivara), rio Paranapanema, bacia do alto rio Paraná, Brasil, e a importância dos grandes tributários na sua manutenção. Iheringia, Sér. Zool. 95(3): 319-325.

JEDICKE, A., FURCH, B., SAINT-PAUL, U. \& SCHLUETER, U.B. 1989. Increase in the oxygen concentration in Amazon waters resulting from the root exudation of two notorious water plants, Eichhornia crassipes (Potenderiaceae) and Pistia stratoides (Araceae). Amazoniana 11(1): 53-89.

JUCÁ-CHAGAS, R. 2004. Air breathing of the neotropical fishes Lepidosiren paradoxa, Hoplerythrinus unitaeniatus and Hoplosternum littorale during aquatic hypoxia. Comp. Biochem. Physiol. 139(1): 49-53.

JUCÁ-CHAGAS, R. \& BOCCARDO, L. 2006. The air-breathing cycle of Hoplosternum littorale (Hancock, 1828) (Siluriformes: Callichthyidae). Neotrop. Ichthyol. 4(3): 371-373.

JUNK, W.J., BAYLEY, P.B. \& SPARKS, R.E. 1989. The flood pulse concept in river-floodplain systems. Can. J. Fish. Aquat. Sci. 106: 110-127.

LANGEANI, F., CASTRO, R.M.C., OYAKAWA, O.T., SHIBATTA, O.A., PAVANELLI, C.S. \& CASATTI, L. 2007. Diversidade da ictiofauna do Alto Rio Paraná: composição atual e perspectivas futuras. Biota Neotrop. 7(3): http://www.biotaneotropica.org.br/v7n3/pt/ abstract?article+bn03407032007 (último acesso em 13/11/2007).

LOWE-McCONNELL, R.H. 1999. Estudos ecológicos de comunidades de peixes tropicais (A.E.A.M. Vazzoler, A.A. Agostinho \& P.T.M. Cunningham, trad.). Editora da Universidade de São Paulo, São Paulo.

MAGURRAN, A. E. 2004. Measuring biological diversity. Blackwell Science Ltd., UK.

MAITLAND, P.S. \& MORGAN, N.C. 1997. Human impacts. In Conservation management of freshwater habitats: lakes, rivers and wetlands (P.S. Maitland \& N.C. Morgan, eds). Kluwer Acad. Publishers, Boston, p. $45-85$.

MENDONÇA, F.P., MAGNUSSON, W.E. \& ZUANON, J. 2005. Relationships between habitat characteristics and fish assemblages in small streams of central Amazonia. Copeia (4): 751-764.

MESCHIATTI, A.J. 1998. Ecologia de peixes associados às macrófitas em duas lagoas marginais do rio Mogi-Guaçu. Tese de doutorado, Universidade Federal de São Carlos, São Carlos.

MESCHIATTI, A.J., ARCIFA, M.S. \& FENERICH-VERANI, N. 2000. Fish communities associated with macrophytes in Brazilian floodplain lakes. Environ. Biol. Fish. 58(2): 133-143.

MIOTO, J.A., SIMÕES, N.S. \& MANO, V.G.T. 2000. Caracterização das pequenas centrais hidrelétricas. In Pequenas centrais hidrelétricas no estado de São Paulo (CSPE org.). Páginas e Letras, São Paulo.

MORAES, A.J. 2001. Manual para avaliação da qualidade da água. RIMA, São Carlos.

NOVAKOWSKI, G.C., HAHN, N.S. \& FUGI, R. 2007. Alimentação de peixes piscívoros antes e após a formação do reservatório de Salto Caxias, Paraná, Brasil. Biota Neotrop. 7(2): http://www.biotaneotropica.org.br/v7n2/pt/ abstract?article+bn04107022007 (último acesso em 13/11/2007).

OLIVEIRA, E.F., LUIZ, E.A., AGOSTINHO, A.A. \& BENEDITO-CECILIO, E. 2001. Fish assemblages in littoral areas of the upper Paraná river floodplain, Brazil. Acta Sci. Biol. Sci. 23(2): 369-376.

OLIVEIRA, E.F., GOULART, E. \& MINTE-VERA, C.V. 2003. Patterns of dominance and rarity of fish assemblage along spatial gradients in the Itaipu reservoir, Paraná, Brazil. Acta Sci. Biol. Sci. 25(1): 71-78.

OLIVEIRA, A.K. \& GARAVELLO, J.C. 2003. Fish assemblage composition in a tributary of the Mogi-Guaçu river basin, southeastern Brazil. Iheringia, Sér. Zool. 93(2): 127-138. 
OKADA, E.K., AGOSTINHO, A.A., PETRERE Jr., M. \& PENCZAK, T. 2003. Factors affecting fish diversity and abundance in drying ponds and lagoons in the upper Paraná river basin, Brazil. Ecohydrol. \& Hydrobiol. 3(1): 97-110.

PELICICE, F.M. \& AGOSTINHO, A.A. 2006. Feeding ecology of fishes associated with Egeria spp. patches in a tropical reservoir, Brazil. Ecol. Fresh. Fish 15(1): 10-19.

PENCZAK, T. \& AGOSTINHO, A.A. 1997. Aplicação do método de comparação de abundancia/biomassa $(\mathrm{ABC})$ na comunidade de peixes do reservatório de Segredo. In Reservatório de Segredo: bases ecológicas para o manejo (A.A. Agostinho \& L.C. Gomes, eds.). EDUEM, Maringá, p. 203-211.

PEREZ Jr., O.R. \& GARAVELLO, J.C. 2007. Ictiofauna do Ribeirão do Pântano, afluente do Rio Mogi-Guaçu, Bacia do Alto Rio Paraná, São Paulo, Brasil. Iheringia, Sér. Zool. 97(3): 328-335.

PETESSE, M.L. 2007. Caracterização da ictiofauna da represa de Barra Bonita (SP) e adaptação do Índice de Integridade Biótica (IIB). Tese de doutorado, Universidade Estadual Paulista, Rio Claro.

PETESSE, M.L., PETRERE Jr., M. \& SPIGOLON, R.J. 2007. The hydraulic management of the Barra Bonita reservoir (SP, Brazil) as a factor influencing the temporal succession of its fish community. Braz. J. Biol. 67(3): 433-445.

PETRY, A.C., AGOSTINHO, A.A. \& GOMES, L.C. 2003. Fish assemblages of tropical floodplain lagoons: exploring the role of connectivity in a dry year. Neotrop. Ichthyol. 1(2): 111-119.

REIS, R.E. 2003. Family Callichthyidae (armored catfishes). In Check List of the Freshwater Fishes of South and Central America (R.R. Reis, S.O. Kullander \& C.J. Ferraris Jr., orgs.). EDIPUCRS, Porto Alegre. p. 291-309.

SÁNCHEZ-BOTERO, J.I., FARIAS, M.L., PIEDADE, M.T. \& GARCEZ, D.S. 2003. Ictiofauna associada às macrófitas aquáticas Eichhornia azurea (SW.) Kunth. e Eichhornia crassipes (Mart.) Solms. no lago Camaleão, Amazônia Central, Brasil. Acta Sci. Biol. Sci. 25(2): 369-375.

SANTOS, J.E.S. \& PIRES, J.S.R. 2000. Estudos integrados em ecossistemas: Estação Ecológica de Jataí. RIMA, São Carlos, v.2.

SILVA, A.R.M., SANTOS, G.B. \& RATTON, T. 2006. Fish community structure of Juramento reservoir, São Francisco river basin, Minas Gerais, Brazil. Rev. Bras. Zool. 23(3): 832-840.

SILVA, E.F., MELO, C.E. \& VÊNERE, P.C. 2007. Fatores que influenciam a comunidade de peixes em dois ambientes no baixo rio das Mortes, planície do Bananal, Mato Grosso, Brasil. Rev. Bras. Zool. 24(2): 482-492.
SMITH, W.S. \& BARRELLA, W. 2000. The ichthyofauna of the marginal lagoons of the Sorocaba river, SP, Brazil: composition, abundance and effect of the anthropogenic actions. Braz. J. Biol. 60(4): 627-632.

SMITH, W.S., ESPÍNDOLA, E.L.G., PEREIRA, C.C.G.F. \& ROCHA, O. 2002. Impactos dos reservatórios do médio e baixo rio Tietê (SP) na composição das espécies de peixes e na atividade de pesca. In Recursos hidroenergéticos: usos, impactos e planejamento integrado (Programa de Pós Graduação em Ciências da Engenharia Ambiental, orgs.). RIMA, São Carlos, p. 57-72.

SMITH, W.S., PEREIRA, C.C.G.F., ESPÍNDOLA, E.L.G. \& ROCHA, O. 2003. A importância da zona litoral para a disponibilidade de recursos alimentares à comunidade de peixes. In Ecótonos nas interfaces dos ecossistemas aquáticos (R. Henry, org.). RIMA, São Carlos, p. 233-248.

SOUZA-HOJO, D.M. 2008. Composição e alimentação da ictiofauna da área de influência da UHE Funil, localizada no rio Grande, município de Perdões, MG. Dissertação de mestrado, Centro de Aqüicultura da Universidade Estadual Paulista, Jaboticabal.

TUNDISI, J.G. 1981. Typology of reservoirs in Southern Brazil. Verh. Internat. Verein. Limnol. 21: 1031-1039.

TUNDISI, J.G. 2003. Água no século XXI: enfrentando a escassez. RIMA, São Carlos.

VALENTIN, J.L. 2000. Análise de agrupamento. In Ecologia numérica: uma introdução à análise multivariada de dados ecológicos. Interciência, Rio de Janeiro. p. 53-65.

VAZZOLER, A.E.A.M. 1996. Biologia da reprodução de peixes teleósteos: teoria e prática. EDUEM, Maringá.

VIEIRA, L.J.S. \& VERANI, J.R. 2000. Diversidade e capturabilidade em comunidades de peixes de lagoas marginais do rio Mogi Guaçu submetidas a diferentes graus de assoreamento. In Estudos integrados em ecossistema: Estação Ecológica de Jataí (J.E. dos Santos \& J.S.R. Pires, eds.). RIMA, São Carlos, p. 831-850.

WOLDA, H. 1981. Similarity indices, sample size and diversity. Oecologia 50(3): 296-302.

ZAR, J.H. 1999. Biostatistical analysis. 4 ed. Prentice Hall, New Jersey.

Recebido em 24/03/08

Versão reformulada recebida em 21/04/08

Publicado em 02/06/08 